\title{
Key features of therapeutic social work: the use of relationship
}

JOHN SUDBERY

Summary This article summarizes key features of therapeutic social work from a psychodynamic perspective. The emphasis throughout is on the social worker's use of relationship. The article's starting point is that whatever their other concerns-welfare administration, advocacy, social action, practical assistance, or social control, for example-social workers have a core responsibility for outcomes which are therapeutic, empowering and developmental. The key components of relationship are analysed as attention to basic need, response to aggressive impulses and the lessening of punitive self-criticism. These are located within the conceptual framework (set out earlier in the article, with examples) of transference, countertransference and the punitive superego. Such work requires a managerial supervisory function which supports and enables this use of relationship. Core components are the provision of staff support and suitable work arrangements and expectations.

\section{Introduction}

This article presents a psychodynamic overview of key features of the social worker's use of relationship. Its purpose is to indicate how psychodynamic insights can assist the social worker to be of maximum helpfulness in the difficult and complex human situations in which they are involved.

The first section presents a view of what social work is and the nature of the problems it tackles in such a way as to highlight the central importance of relationships. This material would be accepted by many who do not regard themselves as psychodynamic thinkers or practitioners; it highlights the inadequacy of descriptions which (sometimes by default) emphasise only an administrative function or social action or practical assistance.

The second section begins by summarising components which form a generically psychodynamic perspective on social work, highlighting the therapeutic (developmental) potential of the relationship, the dynamics of transference and countertransfence and the practical ('frame') arrangements seen as necessary for the relationship to be effective in this way. Any specific model for practice will be more elaborated than this, and the section concludes by detailing one possible elaboration - the necessity of attending to the individual's relationship with themselves, as well as external problems.

The final section recapitulates the messages for practice which arise from taking this perspective-the importance of focussing constantly on the relationship between worker and service user, the need for management and supervision which prioritises the provision of appropriate arrangements, and the necessity of staff support.

\section{Social work, relationships and emotions 1}

Partial views of social work

Amongst those who also tackle the varied problems presented to social workers are included: politicians and social activists; administrators of financial or other material assistance; lawyers; the police; community organisers; nurses and other health workers; psychologists; teachers; religious advisers; and a wide variety of volunteers who work in different ways according to the nature of their association.

In many cases an effective social work response contains elements of process and outcome which are also characteristic of these different perspectives. One consequence of this is that either the problem itself or social work activity may be partialised-defined with reference to one of these perspectives only. For example, 'social work can be defined only in terms of [its] statutory functions' (Brent, 1985); 'the problems of poverty and housing require community 
and political action, not individual casework'; $; 2$ the problem of sexual abuse is essentially a societal issue, of male power'; 'the social worker's job has to be efficient assessment and care management'; problematic childhood behaviour or difficulties in adult emotional life may be seen as essentially matters for psychological or medical treatment.

Problems in relationships may thus be viewed as either the subject of commonsense human solutions or the province of 'marriage guidance services', 'counsellors', 'psychotherapists', regarded as non-social work disciplines. In either case, administrators and policy makers may seek to define social work outcomes in quantifiable measures and targets which take insufficient account of the lived experience of users of services.

\section{Expertise in relationships is central to effective social work}

Given this context, it is important to be clear that a core component of social work is the ability to respond to people's emotional needs, to their impulse for emotional development, and to the difficulties they experience in forming or maintaining relationships. Many of the problems have origins in societal dynamics (of racism, gender inequality and economics for example), and social workers have important roles in ensuring material and financial resources. But whatever other dimensions they may have, problems of child abuse, problems of mental health, of violence in intimate relationships, of bereavement in later life, all involve perturbations in emotions and relationships. The present article is an introduction to core elements of the psychodynamic social work tradition which over decades has analysed the elements involved in an effective response, both in overview (for example: Beistek, 1961; Ferrard \& Hunneybun, 1962; Woods \& Hollis, 1964/1991; Salzberger-Wittenberg, 1970; Woodmansey, 1972; Waddell, 1989; Preston-Shoot \& Agass, 1990; Howe \& Hinings, 1995) and in meticulous detail (for example: Mattinson \& Sinclair, 1979; Biggs \& Woolfe, 1998; Cooper \& Webb, 1999; Couper, 2000; Treacher \& Katz, 2000; McCluskey \& Cooper, 2000; Hollway, 2001).

Occasionally, the social worker's attention to feelings and relationships need only be courteous and considerate alongside the effective completion of some more administrative task. More often, the successful accomplishment of tangible tasks is possible only if considerable priority is placed on the individual's emotional and relationship-based needs. And in many areas, assisting people to establish and maintain satisfactory interpersonal relationships, helping them with their emotional difficulties, is the core social work task. Helping adults with the problems of child-rearing or difficulties in their own relationships, preventing child abuse (as explored, for example in Turney \& Tanner, 2001) and dealing with its after effects, working with those who wish to kill themselves and with those who face their own death-all these and many others are tasks whose successful accomplishment requires expertise in relationships and whose outcome is appropriately described as therapeutic. Social workers-if suitable working arrangements are supported-are able to provide the relationship which is the medium for the amelioration of these problems.

This is starkly illustrated by the words of a client who gave me (as manager) a copy of the letter which she had sent to her local Councillor (the title in the UK for the representative politician in the local assembly). Following publicity about possible cuts to social services, 'Mandy' (not her real name) had written to express her fears that her social work service would be withdrawn. Although she had experienced grave practical problems in her life, and had made use of many material services, the reason she gave why she needed her worker was that 'she talks to me, helps me out with my problems-she helps me when I'm feeling down and upset-she helps me to be good with my baby'. This (relationship-based) service was needed because, in the words of the letter, 'If I didn't have nobody I just lose my rag. I lost my children cause I lost my rag. I've got another one, I'm keeping and I'm happy ...'. Thus the problems she identified were that the State had taken her first children (causing, no doubt, the greatest hurt that can occur in most people's lives) and that her violent temper had 
been the cause of this. The outcomes for which she expressed appreciation are that she has a child-perhaps the most important relationship in her life.

This service was provided by a voluntary social work organisation whose funding came partly from the local government. We worked closely with the local State services (the Social Services Department) and indeed, Mandy had been introduced to us by the Department. The letter made no mention of Mandy's hatred towards the social worker who had responsibility for her first children, and who supported this use of the unit for her. These dual themes, of neediness and of violent hatred, are themes which must be seen as fundamental to the analysis which is presented in the remainder of this paper.

Some models of public service (and some models specifically of social work practice) conceptualise people as rational actors using logic and systematic problem-solving strategies to meet their own needs. Whilst not denying these capacities and capitalising on them to the maximum, the approach explored in this article emphasises the logic of emotions. As Howe and Hinings (1995) point out so clearly, this logic (of emotions which may be recognised or unrecognised) can work in very different directions from intellectualised rationality.

The use of self in social work practice The primary resource in this work is the social worker themselves and their use of relationship. The purpose of social work is empowerment, the approach chosen must be participative and the starting point (as well as the continuing medium) is the social worker's response to someone making demands, in distress, requiring service. Despite this neediness, the immediate context may be that the person is required by an external force to see the social worker, and the worker at that point has no way of knowing whether a productive working relationship can be formed. To the degree that the requirements of the service user involve perturbed emotions and difficulties in relationships, these will inevitably be brought into the relationship with the worker. Given the establishment of a basic working relationship, it is the quality of the social worker's response which determines the effectiveness of service. Some professions have separated out the relationship response to the person as 'customer care' alongside other more technically specified services-the doctor's 'bedside manner', the agency's 'customer care policy', the nurses' 'tender loving care'. Social work, on the other hand, has long-developed traditions which recognise the frequent inseparability of the relationship response from the 'core task'. The components of a relationship which is developmental and liberating are integral to the other aspects of social work-which may be to do with material assistance, living circumstances or societal dynamics. As is implicit in Mandy's letter, users of services are seen to be denied their rights unless social workers (and others) provide a relationship which is developmental and therapeutic.

There are various ways in which close analysis can be made of relationship-based work. The next section of this paper highlights insights derived from the psychodynamic perspective in social work. It emphasises the therapeutic (developmental) potential of the relationship, the dynamics of transference and countertransference, the practical ('frame') arrangements seen as necessary, and the internal psychodynamics pertaining to the individual's relationship with themselves.

\section{Using psychodynamic insights in social work practice}

The problems experienced by clients (as well as those, of course of staff) are the combination of the external difficulties confronting them (whether these are practical, interpersonal or social in a broader sense) and any internal difficulties they experience. Although this conceptualisation is relevant to the work of many of the human services, it is almost definitional of social work, and it explains its characteristic focus on the external and internal, subjective and objective, individual and social. Any subjective element of the difficulties (the individual's emotional makeup, their difficulties and strengths in relationship) will be brought into the 
relationship with the worker. It is characteristic of psychodynamic work to recognise how the quality, care and integrity of the worker's response can enable development, maturation and therapeutic progress.

The description of this model as 'psychosocial' (Woods \& Hollis, 1964/1991) is entirely appropriate, but it should be noted that this is a different use of the adjective from its later more generic use by psychologists, psychiatrists and in medical discourse. The latter refers to any therapy which is provided by human influence rather than drugs or technology. These may for example include didactic, instructional, technique-based work in which the subjective encounter is of little significance, very different from the 'psychosocial model' of social work with its emphasis on the quality of relationship. The model is 'holistic', but it is a specific use of that adjective because for example a holistic nursing assessment of need will not necessarily be based on the individual nurse's relationship with the patient as central. It is distinct from other traditions within psychoanalytic and psychodynamic thinking because it explores the therapeutic relationship which may also actively engage with the client's real external life-their finance, housing, daily living, their care of children. In psychodynamic terms, this implies that in social work the transference is not based solely on a fantasy relationship, but on the experience of a real person (Irvine, 1956/1979). It is to this term that the article turns next.

\section{Transference}

In referring to 'transference', attention is being directed in a particular way on the client's experience of the worker; importance is being attached to features of that experience which indicate the ways in which the worker needs to respond in order for there to be an emotionally developmental outcome. The term represents a key concept in psychodynamic thinking, it has many facets, and in the 90 years since Freud first used the term, writers and practitioners have given it a range of (related) connotations (Sandler et al., 1992, chs 3-4). The term derives from psychoanalysis, and some would argue that its use should be restricted to that specific context-a relationship which exists only within carefully bounded encounters that take place for 50 minutes three to five times a week for several years. Adopting this stance would require us to use a phrase such as 'features analogous to the transference' when discussing related characteristics which occur in other helping relationships.

Whatever its debatable characteristics, 'transference' refers to the propensity of a helping relationship in the present to have echoes of the situation when the user of service was a child and needed assistance or care from their parent. 'The patient sees in him the return, the reincarnation, of some important figure out of his childhood or past, and consequently transfers on to him feelings and reactions which undoubtedly applied to this prototype' (Freud, 1940/1949).

That earlier relationship, and incidents within it, will have had certain qualities, positive or negative-that the child or infant was totally confident that they would receive help, for example, or that they were angry and demanding, or that they were lonely and fearful of rejection. The parent may have been accepting and positive or scornful, critical and punitive, even habitually rejecting, malicious, violent or exploitative. The echoes of these earlier experiences come from many layers - from the earliest preverbal infantile relationships, through childhood occasions such as the first day at school, to adolescent interchanges. In relation to this propensity to 'transfer' on to him characteristics which were unrealistic in the present, which belonged to earlier authority figures in his patients' lives, Freud noted that 'what at first seemed a great obstacle became the therapist's greatest ally' (Freud, 1917).

For if the worker is relating with genuine care and integrity, and working within suitable arrangements, the relationship provides not merely a stage on which past experiences are reenacted, but also the opportunity in relation to current problems to recapture the strength derived from positive aspects of earlier attachments, and experience a different response to problematic elements whose effects still continue. 
In the transference, whatever the client's conscious awareness of and ability to verbalise problems in relating, the issues are unerringly dramatised. Emotional issues left unresolved from earlier experiences-abandonment, abuse, rejection-are presented again. The 'positive transference' whether understood as the confidence-inducing components of the here-andnow relationship, or as the aspects of childhood experience which were nurturing and reliableprovides the basis on which difficult elements are tackled. In the transference relationship, as Paula Heimann put it, 'repetition can turn into modification' (Heiman, 1956/ 1989, pp. 111, 119). A response based on non-possessive warmth can allow the client to find a resolution not available to the vulnerable child.

Bella (then 45 years old) and I first met after her 17-year-old daughter Kylie had left Care, was pregnant, and was refusing to have any contact with her. There were apparently fears about Kylie's well-being and the safety of her unborn baby. Bella knew we were a voluntary organisation and had some idea of our work-we helped families with severe difficulties, including children who had been abused and parents who harmed their children-because she had acquaintances who used us. Bella had an antagonistic relationship with the social services department.

The overt purpose of Bella's unannounced visit to the unit was not really clear to me at that time. She appeared to be complaining (about the unit) that insufficient help was and had been offered, although she was clear that we had no prior knowledge of herself or her family. She was not primarily asking us if we could help her daughter. She accepted an invitation to come back again, and subsequently to be introduced to her own worker. She would (sometimes with reservations) agree to arrangements to meet her worker, but although she would come to the unit at the relevant time, it would not be uncommon for her to sit in the kitchen where parents and children could socialise and refuse to see her worker. She was sometimes antagonistic and bitterly resentful about social workers, but she took part in and enjoyed a range of activities and facilities which were available.

Clarity and collaboration between the unit and the social services department came to be very important, as her daughter Kylie came to use the unit's services, and concerns about the young baby had to be managed on a daily basis. It became evident that there were significant problems with Bella's younger children. The bleakness and oppressive qualities of Bella's life (both in the present and the past) became increasingly clear to her worker as Bella came to use the unit and her worker consistently. She made it clear how much she valued the help offered.

This account gives a generalised picture of Bella's relationship to the Unit. Its features however, were evident in living detail in her relationship with her social worker, and these illustrate the meaning of transference-how states of mind originating in the past may be experienced/recreated in the present helping relationship.

In the transference, the unit/the worker symbolises (and apparently behaves as) someone who helps babies and parents. Part of Bella's state of mind is that at this crucial stage of her life, estranged from her daughter, realistic about the vulnerability of her granddaughter, and in the context of her own abusive childhood, she is going to be persistent in seeking help despite the difficulties she finds as she seeks it. The social worker's task is to support and respond to this courage, especially when faced with behaviour which reflects the hostility and suspicion which Bella feels towards people who are experienced by her as unhelpful and punitive. For the other dimension of Bella's transference is that people who come in the guise of parental figures ought to be caring but in fact are hurtful and damaging.

As can often happen, Bella's responses has echoes of the behaviour she herself was contending with. The worker 'knows how she feels', and more important than any advice is 
the experience of a persistent equable response to the challenges this presents. This support in turn helps her to persist with her daughter even when faced with rejection-she knows 'someone is on her side'. It is as if a 'virtuous spiral' of tolerance is set up rather than a vicious circle of frustration and rejection.

There are several respects in which the tradition of psychodynamic therapeutic social work has placed its own characteristic emphasis on the more general traditions in relation to transference. Psychoanalysis potentially presents the patient with a 'blank screen' (sometimes conceived as a neutral 'mirror') in which transference is understood as a fantasy relationship. Social work on the other hand often intervenes in people's lives, so that the external reality of the relationship and the specific characteristics of the worker are inescapable in the transference aspects of social work. This may be linked to the severity of the problems experienced by users of social work-many clients would not respond to an invitation to tackle their problems by keeping an appointment for a 'talking consultation'. The social worker (as happened with both 'Mandy' and 'Bella') has actively to reach out and demonstrate helpfulness in practical ways, even if the problems may ultimately only be tackled by personal interaction, by interpersonal support and by emotional development. The 'transference' in social work is thus inextricably linked to real characteristics and behaviour of the worker as well as the expectations, emotional makeup and previous experience of the client. Within their participation in real-world negotiations, however, and genuine commitment to the well-being of the client in practical as well as verbal interchanges, it remains important for the social worker to be emotionally 'quiet' and receptive if the transference is to emerge as a medium for emotionally developmental work.

Perhaps because of agency function of arranging practical help and 'social policing', it is common, certainly in the UK, for agencies to seriously neglect that the most appropriate means of tackling problems which fall within their remit will often require regular supportive comfortable 'interviews'. This neglect is expressed in the lack of adequate facilities, dearth of relevant supervision, and management which doesn't prioritise this activity (Howe \& Hinings, 1995).

\section{Countertransference}

The worker, too, is human, and 'countertransference' refers to aspects of the worker's experience of the client. As with 'transference', different theoretical formulations emphasise different aspects of this experience, and indeed define it with reference to different components (Sandler \& Dare, 1992). All would include the understanding that the (worker's) experience in the present contains echoes-reawakenings or re-experiencing-of the past, which may not be related to the present reality of the client they are assisting. Thus, for example, a particular female worker faced with a bullying older man who attempts to browbeat and belittle her may understandably feel responses which echo those when as a child she coped as best she could with a father who intimidated her.

These responses-of feeling powerless, hurt, rebellious, for example-will be different from those she needs to express as she is relating as an adult so as to remedy the emotional pain (and associated defensiveness) of her client. In psychoanalytic terms, to respond therapeutically she needs to tune into and respond within the client's transference which is rooted in a re-experiencing of the relationship to earlier authority figures. His arrogance and aggression is a maladaptive response (it could prevent him getting the emotional support and relationship he needs), but it is rooted in situations in the past in which similar responses served a positive function. In this example, the point is not that the worker should suppress or control the response she experiences within her. It is important, however, that her professionalism results in her not venting the feelings on the client or acting them out. They indicate the thoroughgoing support that she or any other worker is entitled to. They point to the quality of the supervision required. She may understandably wish that they did not arise with such vehemence. 'The professional', however, 'is the best of the personal' wrote a distinguished social worker of a former generation (Winnicott, 1964, p. 11), and social work of all the professions has emphasised the importance 
of a natural and genuine human response of worker to client. When feelings are suppressed or controlled, they are often communicated clearly in a relationship.

The countertransference may contain important clues to the experience of the client, so that suppressing or denying them eliminates those clues. The countertransference feelings may be understood quickly by the worker in the social work interaction, or even for experienced workers they may have to be 'held' (neither suppressed nor acted out) until they receive appropriate attention in supervision. At its best this tradition of social work, particularly in the UK, has explored how the countertransference in the social work interview is brought into the work of supervision (Mattinson, 1975). It teases out the different componentsthose which purely relate to the worker and those which provide otherwise unavailable insights about the client's communication; those elements which are productive and those which relate solely to problems for the worker.

This article began by referring to the potential neglect of relationship-based social work. This is not caused solely by external and organisational pressures. The ability to do what is right in the social work role requires the ability to enter into troubled and disturbing subjective experiences whilst thinking, making judgments and behaving appropriately in the more objective world of outside reality and organisational procedures. The research associated with infant observation studies (Bridge \& Miles, 1996; Briggs \& Canham, 1999; Le Riche \& Tanner, 1998) interacts with that from organisational studies (Menzies-Lyth, 1955/1992) to demonstrate graphically that this makes extreme demands on the emotional flexibility of adults. One response to these demands in the countertransference is to retreat to the apparent safety of dealing with procedural or practical issues.

\section{Arrangements}

This developmental use of relationship is maximised only when what the worker offers is experienced as reliable and predictable. People with the most significant difficulties are likely to present well-nigh intractable emergencies, in unpredictable circumstances and at unpredictable times, or to be in contact with the social worker irrespective of their own wishes (as in a Youth Offending Team). The social worker (and most importantly the supervisor and manager) in the model of practice discussed here is seeking to offer planned and predictable time which the user chooses to use rather than is driven by exigency or authority to use. The worker is seeking to provide something which comes to be experienced as supportive and helpful in its own right, which provides assistance in advance of difficult events or is valued independently (and possibly in the face of) any requirement to attend. This will necessarily begin by providing help (if realistic) at the time it is required, but in order to progress, the social worker must be able to offer regular advance appointments in an environment which is welcoming and comfortable. For certain sorts of difficulties, they will to need to provide practical help in advance of crises, and for people whose lives are crisis-ridden, they may well need initially to allocate time frequently in order to be in a position to offer help before emergencies develop. Crucially, however, their work needs to be organised on a basis that a substantial feature of it involves providing regular appointments in comfortable surroundings to people who are not presenting with an immediate crisis.

This is never easy in a social work agency, but an initial step is for supervisors and managers to take the responsibility of regarding it as expected operational practice for their staff-managing expectations, confidentiality, service demands and resources accordingly. It may be feared that such work patterns are unrealistic. But the many contemporary examples of effective work of this nature (for example, McMahon \& Ward, 2001; Walker \& Hext, 2002), the expressed intention of policy makers on some occasions (Department of Health, 1999, p. 10, performance indicator A1) together with a dispassionate view of the overall statistics of social service users and social services staff seem to indicate to me that this is not so.3 The great challenge for policy makers and managers is how to reach a realistic and desirable endpoint from a difficult starting point in an unwieldy and unstable environment. 


\section{Relationship with self}

People have a relationship with themselves as well as with others. Like external relationships, this can be amicable (accepting) or hostile (critical, punitive or destructive). Understanding a negative internal relationship, its causes, dynamics and remedies, is often crucial to social work. It is often provoked by external difficulties and in particular by abuse or rejection in close personal relationships. Tackling it effectively may be an essential component in empowering people in any social work, and where problems focus specifically on emotional states (as in much child care work, in mental health work and in work for example with those who are dying) there is every reason for social workers to take professional care in understanding what is involved in reducing problems of low self-esteem, lack of confidence, self-attack and selfdestruction.

Various models of psychological, social and therapeutic action have their own formulation of this topic. Anti-oppressive theory may prioritise the effects of power differentials (and structural powerlessness) in society; person-centred thinking has emphasised the negative self-concept and incongruence (Rogers, 1961); Winnicottt (1965, p. 142) referred to the development of the 'false self' and Fairbairn (1963) to the 'anti-libidinal ego'. The present discussion will focus on a particular (and conceptually straightforward) psychodynamic formulation of the punitive superego as put forward by Woodmansey $(1966,1972,1989)$.

This proposes that early conflict situations with parents (which of course the child cannot win if the more powerful adult is determined to have their way) results in individuals having two sets of attitudes and feelings-one set which expresses their own basic impulses and another set which are critical and controlling of their basic impulses. Developing the ideas of Freud in a particular direction, Woodmansey describes the former as the basic ego and the latter as the punitive superego. To the degree that the original adults are implacable, the child cannot accommodate both. In such a case, ego and superego are likely to develop separate, although they will interact.

The nature of this interaction is quite clear. The 'punitive superego' is critical, disparaging, punitive and therefore controlling of the basic impulses of the individual, particularly those which tended to prompt parental criticism, punishment, or rejection. These tend to be particularly associated with the individual's responses of aggression and complaint and also their need for affection and comfort (and later, sexuality). Both because parents are likely to act out social prejudices about children's behaviour and because the punitive superego is mobilised in later life when faced with conflict between a hostile world and individual impulses, this disparaging superego is prone in general to take on societal attitudes which are inimical to the individual's actual identity and experience.

The basic ego's experience in this interaction is to be living '24-7' with a harsh (internal) taskmaster which wants it to be other than it actually is, which experiences blame and intolerance for qualities and impulses which are natural and unavoidable. Its responses to this unremitting and constant critical companion are variously guilt for not doing (or being) what is good, frustration and rebellion in the face of such unrealistic strictures (although this may be split off, and suppressed if the original impulses are sufficiently strong, and is in any case initially a self-directed impulse), and ultimately depression of any degree of severity-the result of being constantly put down for responses over which it has no control. This significance of this analysis is that it points to the response required of the social worker, and the final section of this paper reviews the implications for practice.

\section{Making sense of good practice}

This article started with the proposition that an understanding of social work is incomplete if attention is placed solely on task-completion, or solely on societal issues, or solely on material problems. Making sense of good practice in social work necessarily requires attending to relationships. This final section indicates how the elements of psychodynamic thinking which 
have been identified (transference, countertransference, the 'frame', the punitive superego) provide clarity about the elements of good practice in much social work.

Good practice exists in the lived experience of the person who uses the service. It is highly individual and in many aspects this individuality reflects the diverse personalities of workers as well as the specific situation and needs of clients. Different theoretical frameworks are different prisms through which the components of effective work are analysed. Person-centred work places a premium on the core conditions of unconditional acceptance, non-possessive warmth and empathy, but can be seen to focus less on the inevitable dynamics of violence and anxiety within the self and the significance of the transference in therapeutic work. Attachment theory emphasises the biological drive of the human infant to seek relationship and sets out empirically to categorise the 'internal working models' which are the psychological correlates of attachment behaviour (Howe, 1995; Howe et al., 1999); it currently places less emphasis on countertransference and on internal dynamics. Kleinian theory emphasises the vicissitudes of developing emotional life as the infant copes with otherwise overwhelming anxieties and aggression, and the continuing subconscious dynamics which result; in its original expression it is sometimes seen as paying less attention to the impact of actual (sometimes harmful) parental behaviour.

The components identified here-transference, countertransference and the potential of relationship with self to negative because of superego activity-give pointers as follows to elements which will be central to effective therapeutic work.

Focus on relationships

The first message is that in work where therapeutic development is a component, one constant focus of the social worker's attention is on the quality (dynamics) of the working relationship. The relationship difficulties and troubled emotions experienced by the client will in some manner be brought in to that relationship, and the interactions in the relationship are the effective processes at work to remedy difficulties. This does not necessarily mean referring to the relationship (still less does it mean interpreting the transactions in transference terms) - although it may do. But it might mean for example that when a young mother has mishandled a situation with her baby that the worker offers tacit sympathy at her anger at constantly being criticised, comforting because she is finding everything so difficult-rather than offering advice. In the transference, the mother wants support and encouragement in a hostile world-she can receive advice, if she needs it, when she is ready. Meeting her basic need in the transference (meeting her unmet attachment needs in the terminology of attachment theory) is the surest way of defusing her frustration and equipping her to be at her best with her child. Similarly when working with a parent who is destructively punitive of a teenage child and who had got into a battle of wills with them. The social worker's natural tendency to sympathise with the young person and put their side of the story is likely to be an avoidance of a true understanding of the immediate relationship. The parent requires sympathy for the frustrating situation in which they find themselves and the anger and destructiveness it provokes. One cannot express destructiveness and care simultaneously, and only when the felt reasons for anger are understood (by the worker, the authority figure, the current embodiment of earlier parental figures) does it become possible for the feelings to dissipate and alternative parental impulses of care and protection to surface, together with a realistic discussion of ways forward.

\section{Basic help}

Clearly, the fundamental response required is to meet basic needs. By thinking about situations in terms of transference, it is clear what basic needs are. They are continuation, whatever the current age of the client, of the needs of a child-to have the requests attended to (whatever the apparent unreasonableness with which they may be presented), to have care taken over their feelings, to have fears alleviated, to be dealing with someone who is genuinely interested in their well-being, and so on. In purely psychotherapeutic terms these 'basic needs' focus on feelings: the alleviation of anxiety felt at the involvement with someone in 
authority (fear of blame, punishment or rejection), the provision of Rogers' core conditions (empathy, unconditional regard, non-possessive warmth). Social work is often of its nature involved in activities which go beyond the interpersonal interaction of the psychotherapy consulting room, so that 'meeting basic needs' in social casework means acting responsively in terms of agency function-providing information, providing practical assistance as appropriate with accommodation, transport or food, acting as advocate or liaison.

In this therapeutic context, meeting basic needs may have restorative significance. To a degree which may be unknown to the worker at the time, the provision of 'outreach' care or acting as a non-threatening authority figure, taking concern to allay the fears of blame or punishment, being an authority figure who is respectful, supportive and encouraging, may be part of undoing the after effects of disparaging parental figures who belittled the child's fears or who were punitive or interfering. Certainly in the longer term it is precisely these interactions in an enduring relationship which have the potential to lead to a developmental and therapeutic outcome.

\section{Anger and aggression}

Particular importance, then, attaches to an accepting response to impulses which habitually precipitated a destructive encounter in earlier experience. Anger, complaint, aggression and to a lesser extent the need for comfort, intimacy (and thence sexuality) are the impulse of children which are most likely to have been met with threats, retaliation, criticism, rejection or (in the case of comfort or sexualised needs) exploitation.

Whatever the difficulties with resulting behaviour, these impulses arise unbidden, and the stage of therapeutic work which goes beyond an initial response is the worker's evident acceptance of the naturalness of the client's feelings. This acceptance may be an important test for the client of the worker's genuine regard for them-people know it costs little to be polite towards them when they are 'well-behaved' - they are less confident that this will continue if they express criticism, complaint or 'shameful' aspects of their makeup.

The worker can convey acceptance of the client's responses, even if they are not demonstrated in behaviour, indicating how they appreciate that particular refusal or inability to help might understandably arouse resentment whether or not it is expressed. In a similar way, without making interpretations (which may be experienced as accusations), it is often possible by the way the worker talks to demonstrate before the client makes reference to particular feelings that they are not seen as bad, shameful or shocking. Although the message of this section is that this acceptance is particularly important in relation to anger, the processes are clearly also relevant to feelings which people fear are abnormal, such as some responses after bereavement (see the example given in Sudbery \& Bradley, 1996, p. 56) or child-like fantasies about bodies which arise after sexual abuse.

\section{Improving the relationship with self}

The third element in effective helping, which is highlighted by this psychodynamic model, is attention to the quality of a person's relationship with him or herself-to lessen harsh selfcriticism, self-destructiveness and guilt. As Woodmansey (1966, p. 353; 1989, p. 44) has

pointed out, providing acceptance of the impulses referred to in the last few paragraphsacceptance of impulses which in the past resulted in punishment or condemnation-will antagonise the 'superego' aspects of a person, which developed precisely to suppress those impulses. Accepting the naturalness of feeling helpless and passive may alarm a superego which is determined always to be 'strong' and in control; accepting the naturalness of rage, aggression and retaliation may be alarming to the self which has learnt the hard way that these feelings cause retaliation and are only permissible if directed towards targets approved by authority; accepting sexuality and the needs for comfort may be alarming to the superego which is ever vigilant to suppress them.

\section{Support for staff}

The surest way for social workers to understand therapeutic development, to know that using 
help is not a sign of weakness, inadequacy or pathology, is to have received therapeutic support themselves. It is a sad paradox that while it is routine that counsellors and therapists should themselves have received therapy as part of their training, attitudes are often very different about social workers, who deal with the most troubled and disturbed individuals in society. The elements of the needed support mirror those which social workers (and other human service professionals) should offer: basic help (both emotionally about fear anxiety and distress, and practical about advice, physical facilities, adequate resources for service users); understanding of their anger and aggression (which is likely to be prompted by the work-clients dramatise their own difficulties in relating, the organisation fails vulnerable people); and support in the pressures to blame themselves (this work has a particular propensity to provoke self-blame-social workers are involved in the most critical aspects of people's lives and yet may be unable to help, so that their clients die, may kill themselves, may be severely damaged by the system of which the social worker is a part, and social workers may see vulnerable children hurt by their parents when they were charged to ensure that abuse did not occur).

\section{Conclusion}

In this article, it has been possible to summarise only the outline of a psychodynamic understanding of relationships. In every piece of work, what matters is the live details of the human contact between worker and user of service, the human care and concern, not the accuracy of theory (which is a way after the event of making sense of what matters). Understanding this detail is often the route to a deeper understanding of relationships, and it has been possible here only to point towards some of this detail-how it is for example that a professional relationship in adulthood can go towards meeting basic needs which were never met in an abusive childhood, and can thereby strengthen a person in the pressures of parenthood; how it is that accepting and sympathising with the angry outpourings of a frustrated parent about their child can strengthen them to be tolerant when they are with that child later. The generalisations, set within coherent theory, which have been selected for attention are the transference, countertransference, and the punitive superego. The first represents the propensity of the client's relationship with the worker both to embody the emotional difficulties and also to provide a medium in which the effects of earlier difficulties can be alleviated. The second recognises the significance of the worker's own emotional response. The third highlights the importance of assisting people with their relationship with themselves (which may be harsh and punitive) as well as their ability to relate to others.

\section{Notes}

1 In this article, words in quotation marks are from documents which are or were in a public forum; all other personal details are fictionalised, whilst retaining accuracy about the themes on which comment is made. 2 'You are pulling people out of the swamp instead of draining it', Beatrice Webb, the social activist and founder of the LSE said critically-and bitterly-to Octavia Hill, an early social worker in the UK. 3 In the last Local Authority for which I worked, 22,000 members of the public received service annually from 3,000 staff. This makes no allowance on the one hand for brief contacts, for the non-social services staff who also provided social support (CPNs, health visitors, voluntary agencies for example), or on the other for the intensive residential support required by some service users. Nevertheless, on average, each staff member could provide service to about seven clients annually. That current averages in the UK are of a comparable order of magnitude can be ascertained-with some persistence-from the statistics on www.doh.gov.uk/public/pssstaff.htm.

\section{References}

BIESTEK, F. (1961) The Casework Relationship (London, Unwin).

BIGGS, S. \& WoolfE, R. (Eds) (1998) Counselling and Psychotherapy with Older People. Special edition of the Journal of Social Work Practice, 2(12).

BRENT, LONDON BOROUGH OF (1985) A Child in Trust (London Borough of Brent).

BRIDGE, G. \& MILES, G. (1996) On the Outside Looking In (London, CCETSW).

BRIGGS, S. \& CANHAM, H. (Eds) (1999) The Application of Infant Observation to Social Work. Special issue of Infant Observation, 2(2), pp. 1-123.

COOPER, A. \& WEBB, L. (1999) Out of the maze: permanency planning in a postmodern world, Journal of Social Work Practice, 13(2), pp. 119-135.

COUPER, D. (2000) The impact of the sexually abused child's pain on the worker and the team, Journal of

Social Work Practice, 14(1), pp. 9-17.

DePARTMENT OF HEALTH (1999) The Government's Objectives for Children's Services (London, Stationery 
Office).

FAIRBAIRN, W. (1963) Synopsis of an object-relations theory of the personality, International Journal of Psychoanalysis, 34.

Ferrard, M. \& Hunneybun, N. (1962) The Caseworker's Use of Relationship. Mind and Medicine Monographs. FREUD, S. (1917/1929) Introductory Lectures in Psychoanalysis (London, Allen \& Unwin, 2nd edition, 1929) (Part 3, Standard Edition of the Works of Sigmund Freud, pp. 15-16).

FREUD, S. (1940/1949) An Outline of Psychoanalysis (New York, Norton) (Standard Edition of the Works of Sigmund Freud, 23, pp. 141-208).

HEIMAN, P. (1956) Dynamics of transference interpretations, International Journal of Psychoanalysis, 37, pp. 303-310; reprinted in M. TonNESMANn (Ed.) (1989) About Children and Children-no-Longer, pp. 108-121 (London and New York, Tavistock/Routledge).

HoltwaY, W. (2001) The psycho-social subject in 'evidence-based practice', Journal of Social Work Practice,

15(1), pp. 9-23.

HoWE, D. (1995) Attachment Theory for Social Work Practice (Basingstoke, Macmillan).

Howe, D., Brandon, M., Hinings, D. \& SCHofield, G. (1999) Attachment Theory, Child Maltreatment and Family Support (Basingstoke, Macmillan).

HOWE, D. \& HININGS, D. (1995) Reason and emotion in social work practice: managing relationships with difficult clients, Journal of Social Work Practice, 9(1), pp. 5-15.

IRVINE, E. (1956/1979) Social Work and Human Problems (Oxford, New York, Pergamon).

LE RICHE, P. \& TANNER, K. (1998) Observation and its Application to Social Work (London, Jessica Kingsley).

MATtInson, J. (1975) The Reflection Process in Social Work Supervision (London, Tavistock).

MATTINSON, J. \& SINCLAIR, I. (1979) Mate and Stalemate: Working with Marital Problems in a Social Services Department (Oxford, Blackwell).

MCCluskey, U. \& COOPER, C.-A. (2000) Psychodynamic Perspectives on Abuse: The Cost of Fear (London, Jessica Kingsley).

McMahon, L. \& WARD, A. (2001) Helping Families in Family Centres (London, Jessica Kingsley).

PRESton-Shoot, M. \& AgAsS, D. (1990) Making Sense of Social Work; Psychodynamics, Systems and Practice (Basingstoke, Palgrave, formerly Macmillan Press).

ROGERS, C. (1951) Client-Centred Therapy (London, Constable).

Salzberger-Wittenberg, I. (1970) Psycho-analytic Insight and Relationship (London, Routledge and Kegan

Paul).

SAndler, J., Holder, A. \& DARe, C. (1992) The Patient and the Analyst, 2nd edition (London, Karnac).

SUDBERY, J. \& BRADLEY, J. (1996) Staff support in organisations providing therapeutic care, Journal of Social Work Practice, 10(1).

TREACHER, A. \& KATZ, I. (2000) The Dynamics of Adoption (London, Jessica Kingsley).

TURNEY, D. \& TANNER, K. (2001) Working with neglected children and their families, Journal of Social Work

Practice, 15(2), pp. 193-205.

WADDELL, H. (1989) Living in two worlds: psychodynamic theory and social work practice, Free Association, 15, pp. 11-35.

WALKER, D. \& HEXT, J. (2002) A therapeutic social work team in practice, Journal of Social Work Practice,

16(1), pp. 29-37.

WINNICOTT, C. (1964) Child Care and Social Work (Codicote Press).

WINNICOTT, D. (1965) The Maturational Process and the Facilitating Environment (London, Hogarth).

162 JOHN SUDBERY

WoOdmANSEY, A. C. W. (1966) The internalization of external conflict, International Journal of Psychoanalysis,

47, pp. 349-355.

Woodmansey, A. C. W. (1972) The unity of casework, Social Work Today, 2(19), pp. 14-17.

Woodmansey, A. C. W. (1989) Internal conflict, British Journal of Psychotherapy, 6(1), pp. $26-49$.

Woods, M. \& Holus, F. (1991) Casework: A Psychosocial Therapy, 4th edition (McGraw Hill). 